\title{
BAUMSTARK, Reinhold, Rom in Bayern. Kunst und Spiritualität der ersten Jesuiten
}

Paulette Choné

\section{OpenEdition}

\section{Journals}

Édition électronique

URL : http://journals.openedition.org/ifha/1385

DOI : 10.4000/ifha.1385

ISSN : 2198-8943

Éditeur

IFRA - Institut franco-allemand (sciences historiques et sociales)

Référence électronique

Paulette Choné, «BAUMSTARK, Reinhold, Rom in Bayern. Kunst und Spiritualität der ersten Jesuiten », Revue de I'IFHA [En ligne], Date de recension, mis en ligne le 01 janvier 1999, consulté le 22 septembre 2020. URL : http://journals.openedition.org/ifha/1385 ; DOI : https://doi.org/10.4000/ifha.1385

Ce document a été généré automatiquement le 22 septembre 2020

(CIFHA 


\title{
BAUMSTARK, Reinhold, Rom in Bayern. Kunst und Spiritualität der ersten Jesuiten
}

\author{
Paulette Choné
}

Le titre de cette exposition, qui avait été organisée du 30 avril au 20 juillet 1997 au Bayerisches National Museum de Munich, le plus beau musée d'art et d'histoire d'Europe centrale, était inspiré par deux commémorations, le 400e anniversaire de la dédicace de l'église des Jésuites de Munich, St. Michael, et de la mort de saint Pierre Canisius. L'ensemble des études réunies ici et du catalogue des 235 œuvres exposées constitue une somme irremplaçable sur l'activité des premiers jésuites au nord des Alpes. Heribert SMOLINSKY rappelle les grandes lignes de l'histoire religieuse de la seconde moitié du XVIe s., tandis que le P. John O'MALLEY brosse un tableau général des débuts de la Compagnie, et qu'Ilse VON ZUR MÜHLEN examine avec une grande clarté la fameuse "question des images" vue du côté des jésuites, d'un point de vue théorique et surtout pratique. Deux études sont consacrées à la personnalité et à l'activité de Pierre Canisius (Siegfried HOFMANN, Herbert IMMENKÖTTER), deux autres aux relations des ducs de Bavière avec les jésuites (Hubert GLASER) et notamment à la fondation du Trésor de St. Michael par Wilhelm V et son épouse Renée de Lorraine, étude qui nous vaut la reproduction des extraordinaires peintures du manuscrit du Schatzbuch de l'église, représentant les reliquaires (Lorenz SEELIG). L'architecture de l'église (Johannes TERHALLE), son programme décoratif et les fêtes de sa dédicaces (Sabine M. SCHNEIDER) donnent lieu à des développements neufs très documentés, ainsi que le premier noviciat des jésuites en Bavière, à Landsberg (Dagmar DIETRICH). Le catalogue, divisé en six sections (Innovation et changement; Réforme protestante et réforme catholique; Ignace de Loyola fondateur; Les Wittelsbach et la Compagnie de Jésus; La construction de l'église des Jésuites de Munich; Art et Contre-Réforme; Saint Pierre Canisius), mobilisait vingt auteurs au service d'œuvres venues de plus de quatrevingts collections du monde entier. La confrontation de chefs-d'œuvre bien connus et de réalisations inédites ou rarement exposées, le rapprochement d'œuvres dont les techniques et les destinations étaient extrêmement diverses, la présence de reliques, de 
pièces de costume, d'objets liturgiques et de collection, les séquences iconographiques très complètes (sur saint Michel par exemple), tout cela forme un ensemble parfaitement cohérent, dont les arrangements procèdent d'une démarche intellectuelle rigoureuse et généreuse, jamais des modes muséologiques de l'heure. Ce magnifique travail approfondit et perfectionne une partie de la grande exposition de 1980, Um Glauben und Reich. Par la documentation et les analyses qu'il réunit, il constitue non seulement un véritable monument de la Bavaria Sancta mais de l'histoire des débuts de la Réforme catholique.

Paulette CHONÉ 